\title{
The Creative Reproduction of Chinese Ancient Poetry's Phonological Beauty in English Translation*
}

\author{
Zhaohui Yan \\ Foreign Language Department, Zhengzhou University of Light Industry, China
}

\begin{abstract}
Phonological beauty is an important aesthetic feature of poetry. Reproduction of Chinese ancient poetry's phonological beauty in English translation is of great significance. Professor Xu Yuanchong is an accomplished poetry translator who creatively reproduce original Chinese poems' phonological beauty by employing various techniques such as alliteration, end rhyme, repetition, onomatopoeia, etc. This suggests that Chinese poetry's phonological beauty can be reproduced in English translations although they realize their respective phonological beauties through their respective unique devices.
\end{abstract}

Index Terms - phonological beauty, the principle of beauty in sound, creative reproduction

\section{INTRODUCTION}

Every Chinese Character is monosyllabic and tonetic, which makes Chinese a rigoroso and natural poetic language. Therefore, Chinese ancient poetry is matchless as far as the melodious beauty is concerned. Ancient poets composed verses like composing the musical note with Chinese characters. Since Book of Songs, The first collecting of Chinese poems and songs, Chinese poems have been composed for singing. Folksongs and Ballads in the Style of Yue Fu of the Han Dynasty can be sung, poems of the Tang Dynasty can be sung, and every chi-poem of the Song Dynasty has music score. A Japanese scholar ever said, "Chinese poetry is an advanced art of language, and there is no doubt it is the most brilliant in artistic form and the richest in connotation." (Song, 2005, p.124) Some scholars even hold the view that a person without certain knowledge of phonology can not comprehensively understand and appreciate Chinese ancient poems.

Generally speaking, the main function of rhyme is stringing the discontinuous sounds together to form a complete and harmonious tune. The famous Chinese scholar Zhu Guangqian said in his book entitled On poetry, "rhyme is like the thread that strings pearls, and the thread is especially indispensible for Chinese poetry." (Zhu, 1984, p. 128) Therefore, when translating Chinese ancient poems into English, if the translator gives enough attention to the reappearance of the original phonological effects, the phonological beauty of the original is to be appreciated in different linguistic context. Translation is difficult, and poetry translation is the most difficult of all kinds of translations. The reason why a piece of literature is considered to be a poem is to a great degree its rhythmic beauty, except its beauty of artistic conception and ideas. However, the translator always endeavors to reproduce the latter, neglecting the former. Consequently, the translated poems lost most of their artistic value. Readers of translated poems always complain about the monotonousness of the translated verses, suspecting the high reputation of the famous author of the originals. Needless to say, rhythmic beauty is of great significance for a real poem. Zhu Guangqian ever said, "Poetry is a kind of pure literature of rhythm."(Xu, 2006, p.253) Therefore, to reproduce the rhythmic beauty of the original poem is a key point, which deserves the translators' great attention.

\section{The Phonological Beauty of Chinese Ancient Poetry}

The uniqueness of Chinese characters determines the unique charm of Chinese literature. Phonetically, each Chinese character has a single syllable and the four variations in tones give rise to a cadenced rhyme. The musicality of Chinese is ensured by the dominance of the vowel in each syllable and the lack of the duplicate consonant. Lexically, the monosyllable morpheme takes a leading position in Chinese word formation. Grammatically, Chinese centers on sentence order and function word, without morphological changes but with much flexibility in the construction of words and sentences. The feature provides vast room for men of letters of the past ages in their artistic creation. The four tones were established in the Wei, Jin, Southern and Northern dynasties and the writers consciously employed this cadence to enable their works sound rhythmical. In the Tang Dynasty, the strict Regulated Verse was shaped, which requires the exact characters, lines, level and oblique tones, antithesis and rhymes.(Chen, 2011, p. 297) Farewell to Vice-Prefect Du Setting Out for His Official Post in Shu is a good example (ostands for the level tone, $\bullet$ for the oblique):

\footnotetext{
* This research is funded by Ministry of Education of the People's Republic of China (11YJA751011
} 


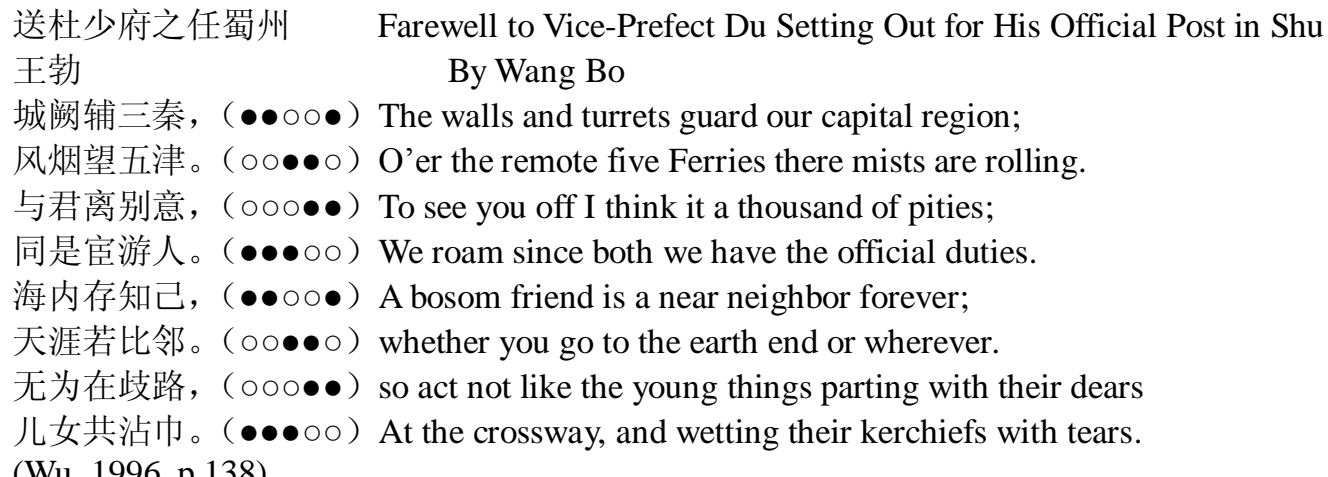

(Wu, 1996. p.138)

This is a five-character regulated verse with 8 lines, and every two lines constitute a couplet in which each line corresponds to the other in level or oblique tones. Each line of the two couplets in the middle corresponds to the next in meaning and the last character of every even line rhyme properly. These designs enable the poem to have a cadenced tone with a special musical charm, which gives rise to not only a pleasant sound but also a supremacy in emotional expression.

In addition to the devices displayed in the above example, ancient poets also employed other devices such as alliteration, assonance and reduplicated words, etc. Li Chonghua made a summarizing comment on the massive use of alliteration and assonance in Zhen Yi Zhai Shi Shuo: "My teacher asked me: 'Poets in the Tang Dynasty used alliteration and assonance in the creation of poetry. Can you tell me the advantages?' I replied: 'From my point of view, assonance gives the sound effect of two pieces of jade knocking each other with a clang; alliteration gives the sound effect of pearls stringing together, sweet and agreeable." (Xu, 2002, p.255) Poets in the Tang Dynasty also wrote numerous great poems by fully employing sound-containing words. Some of them are formed by imitating animals' singing or crying; some of them are descriptions of musical instruments, such as sounds of drums, bells and flutes; and others are sounds of nature, such as winding, raining and falling leaves. All these musical devices create an echoing beauty in sound and make Tang Poetry a marvelous union of sound and emotions.

\section{A Comparison Between Chinese And English Poetic Phonology}

Compared with English, the schwas and stresses of Chinese do not sound so clear. The rhythm of Chinese is back-and-forth, oddevenly vicissitudinary and the rhymed words echo one another. Rhythm makes the monotone literary works sound melodious. To a great extent, Chinese poems' cadence depends on rhyme because the indistinctness between the schwas and stresses will easily result in the disconcertion of sounds, and so in poems rhyme plays the role of echoing on another and achieving cohesiveness.

In some western languages, if several words have the same first consonants and the first syllables of these words are stressed syllables, these words alliterate when they are regularly lined up. In Chinese language, whether two words are rhymed or not is mainly determined by their vowels. Rhymed Chinese characters are always arranged at the end of the sentences. Therefore, in Chinese rhyme is also always called "end rhyme" and the rhymed words are often referred to as "metrical feet". During the process of the development of poetry, Chinese literary circle classified Chinese characters into thirteen groups. The characters of each group are rhymed. Chinese poems are mostly in rhyme, and the rhymed words are usually placed at the end of even lines. Therefore, Ancient Chinese poets adhered to the principle that the second, fourth, and sixth lines must be in rhyme and whether the first, third, and fifth lines are in rhyme or not depends upon different situations. The final sounds of Chinese characters are of various emotions, which can be easily discriminated to Chinese people. For example, the characters rhymed with "ang"/æy/ sound resonant and inspiring, the characters rhymed with "ai"/ai / sounds clear and brisk, the characters rhymed with "ao"/ /// sound calm and steady-going, and so on and so forth.

The rate of using rhymed words of English poems are much lower than that of Chinese poems, but at phonological level different, different rhymes also have different rich connotations. For instance, some western people consider that /a:/ is symbolic of black, /e/is symbolic of white, /i/is symbolic of red, /o/is symbolic of green, and /u/ is symbolic of blue. This is so-called "vowel symbols". It is general believed that some vowels like /e/ , / i/ give people the feelings of "strongness, sharpness, thinness, delicacy", yet other vowels like / u/ , / o/ give people the feelings of "elegance, mellowness, gloominess, lowness". Some consonants like / m/, / n/, / / and / 1/, / r/ implicate the special traits of "smoothness, harmony, volatility, distention". (Yang, 2000, p.376) This suggests that phonological elements, as experts on literature and arts claimed, are of meanings and are the form of life. (Xia, 1993, p.219) But the implicated meanings need the translator to explore and comprehend. As a translator, in order to reproduce the phonological effect, he should first fully understand the onomatopoeia of the poem, and secondly, he should know to what degree the phonological effects depend upon the intertexts. On the basis of the above good understanding of the original, the translator may choose suitable devices to reproduce the phonological beauty of the original poem. (Liu, 2005, p. 75) 


\section{The Theory of BeAuty In SOUND In C-E PoEtry Translation}

$\mathrm{Xu}$ Yuanchong is a very talented and accomplished translator. From his long experience of poetry translation, he put forward the famous theory of "Three Beauties Princile", namely beauty in meaning, beauty in sound, and beauty in form. Beauty in Sound is one of his three principles.

\section{A. Xu Yuanchong as the Advocator of the Theory}

$\mathrm{Xu}$ Yuanchong printed "His 60 translation works are best-sellers both home and abroad and he is the only expert in China who has ever translated Chinese classical poetry into English and French" on his cards. This is absolutely not blind boast of himself, but just affirmation and praise to his abundant works and theoretical achievements for decades. $\mathrm{Xu}$ Yuanchong is a productive translator. He translated John Christopher, The Red and Black, Madame Bovary and other foreign works into Chinese and many Chinese classical novels and poems, like The Romance of West Bower, 300 Song Lyrics, The Book of Songs, Selected Poems of Mao Zedong, 300 Immortal Chinese Poems, etc.. The Romance of West Bower, translated by him, was praised by The Publishing House of Britain as "A work which rivals Shakespeare's Romeo and Juliet on the aspects of artistry and appeal". Moreover, his 300 Immortal Chinese Poems was collected in Penguin Books and published by Britain's most prestigious publisher Penguin Group. In the field of translation theory study, Xu also has excellent achievements and profound impact. "Three Beauties Theory" of C-E translation of Chinese classical poetry is the gem of his theoretical achievements and opens a new chapter for the development of China's translation cause.

\section{B. The Theory of "Beauty in Sound"}

$\mathrm{Xu}$ Yuanchong's “Three Beauties Theory” for poetry translation was enlightened by Lu Xun's viewpoint. In Lu Xun's essay "From Language to Article", he said, "When reciting and studying one Chinese character, one should learn three things-its form, sound and sense: read it aloud to hear its sound, observe its form and know its sense by heart. Only when one's ears, eyes and heart are all involved, the character can be well learned. Chinese articles are also beautiful in three aspects: beauty in sense to move one's heart; beauty in sound to enjoy one's ears and beauty in form to impact one's eyes."(Song, 2005, p.127) Xu Yuanchong thought in poetry translation, translators not only have to transmit the beauty in sense of the original, but also have to transmit its beauty in sound and form as much as possible. Actually, on the premise of firstly reproducing the beauty in sense of the original, $\mathrm{Xu}$ raised the importance of the beauty in sound. Lu Xun said in his Lu Sun's Collection of Letters, "I think apart from content, new poetry must firstly have rhythm and be rhymed, making itself smooth, easy to remember and sing out."(Xu, 2006, p.73) Xu Yuanchong agrees with Lu Xun's point of view and adopts this principle in his poetry translation practice.

Poetry must have tone and rhythm, be rhymed, smooth to read and appeal to the ear. This is Xu Yuanchong's theory of "Beauty in Sound". In the sphere of C-E translation of Chinese classical poetry, Xu advocates that the tradition of translating poetry in the poetic way represented by Herbert A. Giles, professor in the $19^{\text {th }}$ century Cambridge University should be resumed. Translators should correct its shortages, pay attention to the rhythm and rhyme of poetry and put forward the art of translation. They should not apply "Arthur Waley's free verse and straight forward style which abandons the convention of poetry's metrical feet and terms" (Xu, 2006, p. 27), because that will cause "thin poetic flavor, not being able to infuse the world culture with new blood"(Xu, 2006, p.1). Translating prose generally only requires reproducing the beauty in sense, but poetry translation needs to reproduce the beauty in sound as much as possible.

\section{Approaches for Reproducing Phonological Beauty in C-E Poetry Translation}

As a very important aesthetic feature of poetry, phonological beauty endows poems with great vitality. Since Tang Poetry is a musical art, the translation of it not only has to reproduce its beauty in sense, but also has to convey its beauty in sound so as to give readers auditory enjoyment. Xu Yuanchong applies the theory of "Beauty in Sound" in his poetry translation and has created many masterpieces which integrated sound and sense, sound and emotions in a harmonious way. The phonological beauty of Tang Poetry lies in many aspects as mentioned above. However, it is beyond the scope of this paper to cover all the details. What will be illustrated are the reappearance of rhyme and other musical devices of Tang Poetry.

\section{A. The Use of Alliteration}

Alliteration is an old and most common figure of speech in English. It is a kind of phonetic devices, which refers to the repetition of the first souds of two or more close-by words or syllables. The definition of alliteration given by Longman Dictionary of Contemporary English is: "The appearance of the same sounds at the beginning of 2 or more words that are next to or close to each other (as in 'Round the rocks runs the river')." (Wu, 2001, p. 359) Alliteration bears language's beauty in sound and form, making it a unified whole with sound and emotions. With alliteration, language is more expressive and appealing. In Xu's translation, alliteration is used frequently for the effect of musical beauty.

Liu Yuxi, a famous poet of the Tang Dynasty, ever wrote a poem entitled “乌衣巷” (The Street of Mansions). The first two lines of the poem are “朱雀桥边野草花, 乌衣巷口夕阳斜”. Xu Yuanchong translated this sentence into 
"Beside the Bridge of Birds rank grasses overgrow, Over the Street of Mansions the setting sun hangs low."(Xu, 2001, p. 129) $\mathrm{Xu}$ shows his great originality in his translation of this poem. In his translation, each line uses alliteration. "Beside", "bridge", "birds" rhyme with the voiced consonant /b/, adding the rhythm of the translation; "street", "setting", "sun" rhyme with the voiceless consonant /s/, expressing the writer's sadness when he saw the gloomy scene. Reading this translation, one can feel that the music lingers in the air for a long time and slowly fades away.

\section{B. The Use of End Rhyme}

The form of end rhyme is contrary to that of alliteration. "If two or more close-by words in a stich or a phrase repeat the same syllable, the words are rhymed. The function of end rhyme is the same as alliteration, namely adding to the rhythm sensation and expressive force of language." (Luo, 2000, p. 40) Both Chinese and English commonly use end rhyme to achieve special sound effect. But compared with alliteration, end rhyme is better accepted by Chinese people because most Chinese classical poems all use this kind of rhyme, especially Tang Poetry. Because the musical effect of poetry is fulfilled by end rhyme to a large extent and at the same time, end rhyme helps create the sound effect of long or short, fast or slow, high or low, Xu pays much attention to the application of end rhyme and almost all of his translations are rhymed in the end.

晚 春
韩愈
草树知春不久归,
百般红紫斗芳菲。
杨花榆荚无才思,
惟解漫天作雪飞。
(Xu, 2001, p. 62)

Late Spring

By Han Yu

The trees and grass know that soon spring will go away,

Of red blooms and green leaves they make gorgeous display.

But willow catkins and elm pods are so unwise,

They wish to be flying snow darkening the skies.

There are two obvious advantages for Xu Yuanchong to use his theory of "Beauty in Sound" to translate this poem. Firstly, as far as the rhyme is concerned, $\mathrm{Xu}$ uses the theory successfully in reproducing the musical beauty of the original. The rhyme of the original is regular. The whole poem mainly rhymes with “/ei/”. For example, “归”/gui/、“菲” /fei/ and "飞" /fei/ are rhymed Chinese characters, distributed at the ends of the first, second and last line. In Xu's translation, "away" rhymes with "display", while "unwise" rhymes with "skies". The whole translation keeps the regular rhyme pattern of "aabb", which creatively reproduces the "aaba" rhyme scheme of the original. Secondly, the original is full of contrast between the dynamic and the static. “知春” and “唯解” are the static while “斗” and “飞” are the dynamic. In Xu's translation, "know" and "unwise" create the sense of static state while "display" and "darkening" create the sense of dynamic state. (Cao, 2009, p. 135) Xu Yuanchong's diction not only rhymes, but is also one to one corresponding, adding more flavor to the poem.

\section{The Use of Repetition}

$\mathrm{Xu}$ Yuanchong's translations have another distinguishing feature which is the frequent use of repetition. The rhetoric device of repetition includes reduplicated words and structural repetition, both of which involve words. Rhetors classify repetitious phenomena into immediata repetition, intermittent repetition, ploce, symploce, epanodos, paregmenon, polysyndeton, appositon, etc. In the different kinds of repetition, immediate repetition is frequently adopted in poetry translation. Immediate repetition is mainly used for emphasis, but it is also used to express various emotions. What's more, continuous repetition can quicken the rhythm and add musical effect to the poem, creating a sense of continuous succession. It is like repeated tide waves which give readers auditory impacts and leave them an unforgettable impression.

Chinese famous poetess ever composed a verse, “寻寻受受, 冷冷清清, 凄凄惨惨戚戚!” (Xu, 2000, p. 112) Xu Yuanchong translated it like this: "I seek but seek in vain, I search and search again; / I feel so sad, so drear, so lonely, without cheer." (Xu, 2000, p.113) Xia Chengtao, a famous expert on ci-poems ever commented on this Chinese verse, "Lingual sounds and dental sounds are employed alternately and repeatedly for the purpose of expressing the poetess' inward sadness and loneliness. The whole sentence is not only easy to understand, but also sounds melodious." (Xia, 1980, p.203) The continuous use of reiterative locution makes the verse sound full of forlornness, but it is difficult for the translator to fully convey the spirit of the original. However, Xu Yuanchong repeats the words of "seek", "search" twice and the consonant /s/ eight times in his translation, vividly reproducing the sense of sadness of the original.

\section{The Use of Onomatopoeia}

Onomatopoeia is also called onomatopoetic word, imitative word, echo word, echoic word, etc. It is not only a kind of word creation method but also a kind of figure of speech. It adds to the vividness and iconicity of language by the means of imitating the sounds of human beings, animals, etc. The philosophers of the school of naturalism of Ancient Greece believed, "onomatopoeia is doubtlessly the oldest method of word creation, the core of the whole human glossary, and the base of language formation and development." (Liu, 1998, p. 143) Onomatopoeia helps make description lifelike. As a rule, onomatopoeia is used for the purpose of adding vividness or vitality to the description. It can give the readers a feeling that they are really hearing the sound the poet describes.

$$
\text { 诗经・风雨 }
$$


风雨凄凄, 鸡鸣㫮㫮 既见君子, 云胡不夷?

风雨潇潇，鸡鸣胶胶 既见君子，云胡不疹?

风雨如晦，鸡鸣不已 既见君子，云胡不喜?

This is one chapter of the love poem, and every chapter of this love poem starts with two sentences which reflects the girl's emotions by describing her surroundings. In the night, the sounds of rains, roosters, and wind mingled together. The girl in love is missing her lover. The fluctuations of the girl's emotions is vividly displayed by the four mimetic word “凄凄, 㫮㫮, 潚波, 胶胶”. In translating this poem, the reappearance of the onomatopoetic effects is very important. Look at the following version:

Book of Songs $\bullet$ The Raining Night

Cold is the wind and chill the rain,

Hens are cackling loudly.

Now I've seen my good man again,

How peaceful my heart is!

The wind whistles and the rain patters,

Hens are cackling merrily.

Now I've seen my good man again,

How light my heart becomes!

Wind and rain sweep the gloomy sky,

Hens are cackling endlessly.

Now I've seen my good man again,

How joyful my heart feels.

(Yang, 2001, p.19)

Here, the translator translates “风雨潇潚” into “the wind whistles and the rain patters”, employing two mimetic words “whistle"and"patter". “鸡鸣” is translated into “cackling”, vividly imitating the sound of the hens. By the means of mimetic words, the onomatopoetic effects of the original are wonderfully reproduced.

\section{CONCLUSION}

It is of great necessity for translators to use rhyme but not free verse in translating Chinese classical poetry as Chinese ancestors have made use of rhyme for hundreds of years and have made the most splendid achievement in literature. If the translated version is not rhymed, it is hard to say we have kept the artistic mood and style of the original poem even if the beauty in sense of the original has been adequately conveyed in translating.

Chinese poetry and English poetry realize their respective beauty of rhythm. Chinese poets employ end rhyme, antithesis, level and oblique tone, reiterative locution, alliteration, etc; English poets utilizes end rhyme, foot, alliteration, etc. Although the approaches used by Chinese and English poets are different, there is some overlay between them. Through the exploration of pioneering translators, some effective techniques have been created to reproduce the beauty in sound of the original. Doubtlessly, the reappearance of the original beauty of rhyme should be poetry translators' pursuit, which is sure to be achieved with the discovery of more feasible techniques.

\section{REFERENCES}

[1] Cao, Yun. (2011).The Reappearance of the Phonological Beauty in English Translation. Journal of Beijing International Studies University 14(1), 124-131.

[2] Chen, Jiangfeng. (2011). A Guide to Traditional Chinese Culture. Beijing: Beihang University Press.

[3] Liu, Xiaofeng. (2005). Aesthetic Reproduction of "Rhyme" in Translation of Chinese Ancient Poems into English. Journal of Hohai University (Philosophy and Social Sciences) (7)2, 75-77.

[4] Liu, Yingkai. (1998). Phonostylistics in Chinese and English. Guangzhou: Guangdong High Education Press.

[5] Luo, Pinxia. (2000). A Handbook of College English Rhetoric. Shanghai: Donghua University press.

[6] Song, Kai. (2005). The Embodiment of Xu Yuanchong's Three Beauties Principle in his translation of C-E 300 Tang Poems. Journal of Guangdong University of Foreign Studies 18(1), 124-131.

[7] Wu, Juntao. (1996). 300 Tang Poems. Changsha: Hunan press.

[8] Wu, Ping. (2001). A Comparison Between English and Chinese Figure of Speech. Hefei: Anhui Education press.

[9] Xia, Zhifang. (1993). On Literary Image. Shantou: Shantou University Press.

[10] Xia,Chengtao. (1980). Appreciation of Tang and Song Ci-Poems. Tianjin: Baihua Literature and Art Publishing House.

[11] Xu, Luya.(2010). A Guide to Western Rhetoric. Beijing: The Central University for Nationalities Press.

[12] Xu, Yuanchong. (2000). 150 Ci-Poems of the Tang and Song Dynasties. Beijing: Zhonghua Book Company.

[13] Xu, Yuanchong. (2001). Bilingual Edition 300 Tang Poems. Beijing: High Education Press.

[14] Xu, Yuanchong. (2006). Literature and Translation. Beijing: Zhonghua Book Company.

[15] Yang, Xianyi. (2001). Book of Sons. Beijing: Foreign Language Press.

[16] Yang, Zijian. (2000). Comparison and Translation between English and Chinese. Shanghai: Shanghai Foreign Language Education Press.

[17] Yang, Zongyuan. (2009).The Form of Poetry and English Translation of Chinese Poems. Chinese Translation Journal 31 (2), 134-139. 
[18] Zhu, Guangqian. (1984). On Poetry. Shanhai: SDX Joint Publishing Company.

Zhaohui Yan was born in Henan, China in 1976. He received his M.A. in English language and literature from Shanghai Institute of Foreign Trade, China in 2005. He is currently a lecturer in Foreign Languages Department, Zhengzhou University of Light Industry, Henan, China. His research interests include bilingual translation between English and Chinese, cross-cultural communication. 